\title{
BMJ Open Capillary blood islet autoantibody screening for identifying pre-type 1 diabetes in the general population: design and initial results of the Fr1da study
}

Jennifer Raab, ${ }^{1}$ Florian Haupt, ${ }^{1}$ Marlon Scholz, ${ }^{1}$ Claudia Matzke, ${ }^{1}$ Katharina Warncke, ${ }^{1,2,3}$ Karin Lange, ${ }^{4}$ Robin Assfalg, ${ }^{1}$ Katharina Weininger, ${ }^{1}$ Susanne Wittich, ${ }^{1}$ Stephanie Löbner, ${ }^{1}$ Andreas Beyerlein, ${ }^{1}$ Uta Nennstiel-Ratzel, ${ }^{5}$ Martin Lang, ${ }^{6}$ Otto Laub, ${ }^{7}$ Desiree Dunstheimer, ${ }^{8}$ Ezio Bonifacio, ${ }^{9,10}$ Peter Achenbach, ${ }^{1,2}$ Christiane Winkler, ${ }^{1,2}$ Anette-G Ziegler, ${ }^{1,2}$ the Fr1da Study Group

To cite: Raab J, Haupt F, Scholz M, et al. Capillary blood islet autoantibody screening for identifying pretype 1 diabetes in the general population: design and initial results of the Fr1da study. BMJ Open 2016;6:e011144. doi:10.1136/bmjopen-2016011144

- Prepublication history for this paper is available online. To view these files please visit the journal online (http://dx.doi.org/10.1136/ bmjopen-2016-011144).

Received 14 January 2016 Revised 16 March 2016 Accepted 14 April 2016

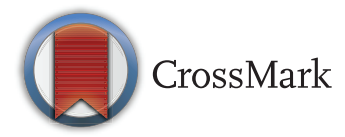

For numbered affiliations see end of article.

Correspondence to Professor Anette-G Ziegler; anette-g.ziegler@helmholtzmuenchen.de

\section{ABSTRACT}

Introduction: Type 1 diabetes can be diagnosed at an early presymptomatic stage by the detection of islet autoantibodies. The Fr1da study aims to assess whether early staging of type 1 diabetes (1) is feasible at a population-based level, (2) prevents severe metabolic decompensation observed at the clinical manifestation of type 1 diabetes and (3) reduces psychological distress through preventive teaching and care.

Methods and analysis: Children aged 2-5 years in Bavaria, Germany, will be tested for the presence of multiple islet autoantibodies. Between February 2015 and December 2016, 100000 children will be screened by primary care paediatricians. Islet autoantibodies are measured in capillary blood samples using a multiplex three-screen ELISA. Samples with ELISA results $>97.5$ th centile are retested using reference radiobinding assays. A venous blood sample is also obtained to confirm the autoantibody status of children with at least two autoantibodies. Children with confirmed multiple islet autoantibodies are diagnosed with pre-type 1 diabetes. These children and their parents are invited to participate in an education and counselling programme at a local diabetes centre. Depression and anxiety, and burden of early diagnosis are also assessed.

Results: Of the 1027 Bavarian paediatricians, 39.3\% are participating in the study. Overall, 26760 children have been screened between February 2015 and November 2015. Capillary blood collection was sufficient in volume for islet autoantibody detection in $99.46 \%$ of the children. The remaining $0.54 \%$ had insufficient blood volume collected. Of the 26760 capillary samples tested, $0.39 \%$ were positive for at least two islet autoantibodies.

Discussion: Staging for early type 1 diabetes within a public health setting appears to be feasible. The study

\section{Strengths and limitations of this study}

- The Fr1da study is population based and conducted as public healthcare research.

- The study uses a novel approach of early diagnosis of type 1 diabetes to prevent diabetic ketoacidosis and improve care.

- The study is performed in children at an age that maximises the likelihood of achieving early diagnosis of childhood diabetes.

- Measurement of psychological impact of early diagnosis will allow impact on family well-being to be evaluated.

- Children positive for a single islet autoantibody in the screening test are not followed.

may set new standards for the early diagnosis of type 1 diabetes and education.

Ethics dissemination: The study was approved by the ethics committee of Technische Universität München (Nr. 70/14).

\section{INTRODUCTION}

Type 1 diabetes is one of the most common chronic diseases of childhood with an incidence that is increasing yearly in European countries. The prevalence of type 1 diabetes in children aged $0-20$ years is $0.3-0.6 \% .^{1-3}$ Symptomatic type 1 diabetes is usually diagnosed by blood glucose measurements at the acute life-threatening onset of this disease. Acute disease onset requires hospitalisation, and is characterised by severe metabolic 
decompensation, a major complication of type 1 diabetes. ${ }^{12}$ The management of metabolic decompensation, and the adaptation of the family to the disease and its treatment are major personal and financial burdens. ${ }^{1}{ }^{2}$ Early diagnosis of type 1 diabetes in the asymptomatic period could help to prevent acute disease onset, and reduce the prevalence of metabolic decompensation and associated hospitalisation. ${ }^{45}$ It may also open the path to population-based disease prevention.

Early diagnosis is possible by the detection of multiple islet autoantibodies. ${ }^{6}$ Nearly all of the children with these biomarkers, regardless of their family history of the disease, will develop clinical symptomatic diabetes. ${ }^{6}$ Therefore, early diagnostic tools should focus on the first years of life, the time when multiple islet autoantibodies usually emerge. ${ }^{7}$ In fact, $80 \%$ of children who develop type 1 diabetes in childhood have multiple islet autoantibodies before 5 years of age. ${ }^{6}$ Thus, if efficient screening is implemented within a public health prevention programme, the majority of future cases of childhood clinical diabetes could be identified in infancy. Preventive teaching, education and monitoring may allow us to prevent severe metabolic decompensation and ketoacidosis, and prepare the children and families for later insulin therapy. These possibilities are being addressed in the Frlda study.

The Frlda study was designed as a model project in order to introduce public health screening of multiple islet autoantibodies (pre-type 1 diabetes) ${ }^{8}$ in Bavaria, Germany. It is assessing 1 ) whether early staging (as outlined in ref. 8) of type 1 diabetes in the context of regular medical checkups in early childhood is feasible and efficient; (2) whether ketoacidosis and hospitalisation of children can be prevented; and (3) whether psychological distress can be reduced through early diagnosis, teaching and care. The Frlda study is also assessing environmental exposures. Its ultimate goal is to introduce a trial platform for the prevention and subsequent management of type 1 diabetes.

Large-scale public health screening programmes require quick and easy blood collection in capillary tubes or dried blood spots, as well as high throughput assays such as widely accepted newborn screening practices. The current assays used to detect islet autoantibodies are sensitive, specific, and standardised. ${ }^{9-14}$ However, in their current format, these are not applicable for high throughput population screening as they are too expensive and labour intensive. Furthermore, there is limited experience of using these assays with capillary blood. ${ }^{15-17}$ To overcome this problem, we have collaborated with RSR Ltd., Cardiff, UK, to develop a screening assay for one-shot detection of autoantibodies to the target antigens glutamic acid decarboxylase-65 (GAD65), insulinoma-associated antigen 2 (IA-2) and zinc transporter 8 (ZnT8) using a sample volume suitable for capillary blood collection. This assay allows us to identify children positive for at least one of these autoantibodies; these children can then be followed through further screening for autoantibodies to GAD65, IA-2, ZnT8 and insulin for the diagnosis of pre-type 1 diabetes. ${ }^{18}$

Here, we report the design of the Frlda study "Early diagnosis and care of type 1 diabetes" which was started in February 2015, and provide the initial results for 26760 children who had been screened by November 2015 .

\section{METHODS}

\section{Study population}

The Frlda study is intended to screen at least 100000 children aged 2-5 years living in Bavaria, Germany, for the presence of multiple islet autoantibodies. Screening started in February 2015 and will continue for about 24 months. Children are screened only once. The screening is offered by primary care paediatricians who have volunteered to participate in the Frlda study.

The optimal age for performing one-off islet autoantibody screening is a compromise between the sensitivity of detecting a large number of children who have already developed multiple islet autoantibodies (better with later screening) and the loss of sensitivity attributed to the progression to clinical diabetes (better with earlier screening). Islet autoantibodies frequently develop within the first years of life, with a peak incidence at 1-2 years. ${ }^{7} 1920$ Therefore, the ' $U$ ' medical checkups in Bavaria scheduled at times after the peak autoantibody incidence represent the best and most practical opportunities to identify children with presymptomatic type 1 diabetes. Therefore, we have recommended that screening is performed in the context of medical checkups at 21-24 (checkup U7), 34-36 (U7a), 46-48 (U8), and 60-64 (U9) months of age, and at any other paediatric visit within these age ranges (http:// de.wikipedia.org/wiki/Kindervorsorgeuntersuchung). By targeting several age-groups, we may facilitate the implementation of screening into paediatric practice, and provide sensitivity estimates for each screening age in order to define the optimal age for population-based islet autoantibody screening.

In Bavaria, there are around 100000 live-births per year and around 1000 primary care paediatricians. Over $99.5 \%$ of children attend preventive medical checkups corresponding to almost 400000 checkup visits per year of children aged $2-5$ years. The checkups comprise physical examinations, hearing tests, assessments of developmental disorders, and allergen tests, but do not yet include blood collection. We anticipate that about half of the primary care paediatricians in Bavaria will participate in the Frlda Study, and around half of the children/families who are offered screening by their paediatricians will participate. Therefore, enrolment of 100000 children is expected to be possible over 2 years (figure 1).

\section{Blood sampling and screening questionnaire}

Capillary blood samples $(200 \mu \mathrm{L})$ are collected by primary care paediatricians, who are reimbursed $10 €$ for 


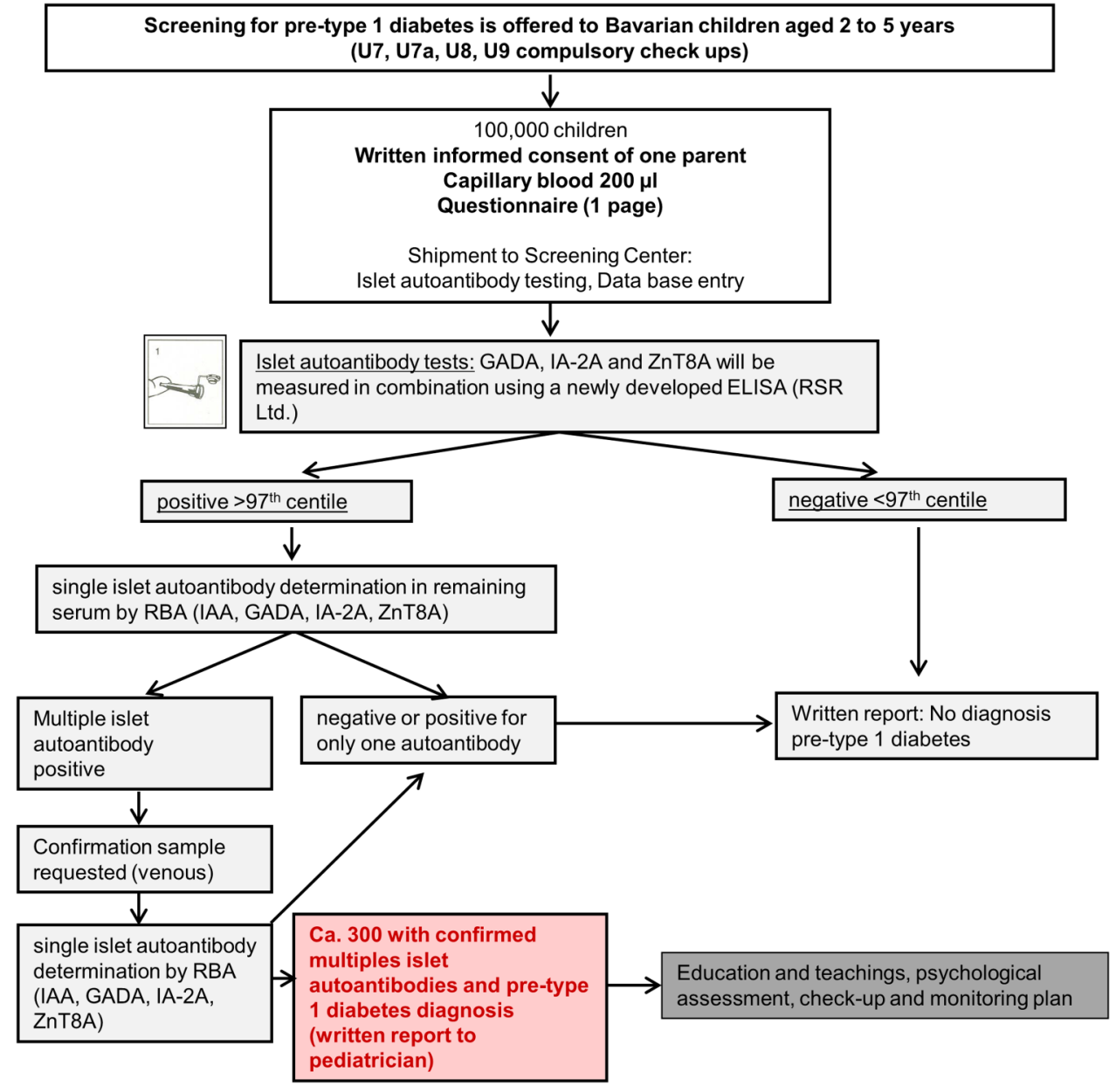

Figure 1 Study design. GADA, glutamic acid decarboxylase autoantibodies; IAA, insulin autoantibodies; IA-2A Insulinoma-associated antigen 2 autoantibodies; RBA, radiobinding assay; ZnT8A, zinc transporter eight autoantibodies.

each child. Paediatricians can store the samples for up to 5 days in a refrigerator, and the return shipments are organised once weekly for each participating site. The child's family completes a one-page questionnaire covering demographic data, type 1 diabetes family history and potentially relevant environmental exposures.

\section{Determination of islet autoantibodies}

Autoantibodies to GAD65 (GADA), IA-2 (IA-2A), and ZnT8 (ZnT8A) are measured in combination using a newly developed multiplex three-screen ELISA (RSR Ltd., Cardiff, UK) using serum prepared from capillary blood. If the three-screen ELISA is positive, the remaining serum will be used to measure GADA, IA-2A, ZnT8A and insulin autoantibodies (IAA) using reference radiobinding assays (RBA). ${ }^{9-14}$ If at least two positive islet autoantibodies are detected by the reference RBA assays, a confirmation venous blood sample is obtained and the diagnosis of pre-type 1 diabetes is made if the confirmatory test is positive. All measurements are done at the screening centre (Helmholtz Zentrum München). The paediatrician who collects the blood is informed of the diagnosis and autoantibody status, and then informs the families.

Children positive for just one autoantibody in the screening test are not followed, and not diagnosed with pre-type 1 diabetes. Risk for children with single islet autoantibodies progressing to diabetes is at a low rate (less than $15 \%$ in 10 years), ${ }^{6}$ which we currently consider too low to report to families. In addition, the screening strategy does not detect children positive for IAA in the absence of other autoantibodies. Adding IAA to the screening of all 100000 children was not considered cost-effective or necessary to identify multiple islet autoantibody positive children. There is no disadvantage in not testing for IAA in the initial screening test as our aim is to identify children with two or more antibodies. Since all children with at least one antibody in the three-screen ELISA are tested for IAA, all children with multiple islet autoantibodies that include IAA will be identified.

On receipt of the capillary blood samples (collected in Microvette $200 \mathrm{Z}$ tubes) at the screening centre, the blood samples are centrifuged at $3000 \mathrm{rpm}$ to obtain serum. Signs of haemolysis are recorded in the database. 
The serum samples are stored at $-20^{\circ} \mathrm{C}$, and tested within 1 week (range $0-14$ days) after receipt. The three-screen ELISA requires $25 \mu \mathrm{L}$ serum for a single well analysis and $50 \mu \mathrm{L}$ for duplicates. The conventional RBAs require $4 \mu \mathrm{L}$ for duplicate analysis of GADA and IA-2A, respectively, $8 \mu \mathrm{L}$ for $\mathrm{ZnT} 8 \mathrm{~A}$, and $20 \mu \mathrm{L}$ for IAA. ${ }^{9-14}$

The 3-screen ELISA assay is performed over 2 days. It is performed using $25 \mu \mathrm{L}$ of serum. All samples with a three-screen ELISA signal above the 97.5th percentile are then tested for GADA, IA-2A, ZnT8A, and IAA using reference $\mathrm{RBAs}^{9-14}$ from the remainder of the capillary blood sample. If there is insufficient blood sample for this procedure, single RBAs of GADA, IA-2A and ZnT8A are prioritised because these require smaller volumes. If necessary, another capillary blood sample is requested from the paediatrician.

For the reference RBAs, the cut-off for venous blood samples corresponds to the 99th centile of values in control children. To compare the autoantibody levels between capillary and venous serum samples, 31 samples from antibody positive and negative children were directly compared before starting the Frlda study. In addition, capillary blood samples covering a range of ELISA values above and below the 97.5th centile were tested for GADA, IA-2A, ZnT8A and IAA in order to determine how appropriate the RBA serum cut-offs were for the capillary blood samples. The haemolytic status of capillary samples was also considered for assessing the distribution of IAA values.

\section{Education and counselling programme}

The parents of children with pre-type 1 diabetes are invited to attend one 3-4h educational programme where they are instructed about urine and blood glucose monitoring, symptoms of hyperglycaemia, pathogenesis of type 1 diabetes, insulin action, and normal and pathological blood glucose levels. The education programme takes place close to the family's place of residence. It is performed by a local paediatric diabetes centre team who have received special training in pre-type 1 diabetes education, and thus allows the family to develop a relationship with their local paediatric diabetes centre. The purpose of counselling is to help the families accept the diagnosis of pre-type 1 diabetes, to cope with it in a positive manner, and to alleviate any anxiety that may arise. The families are provided with a guidebook ('Fr1da-Book'), which was especially developed for the early stages of type 1 diabetes. All families are assigned a contact person (doctor or diabetes educator) from the diabetes team and are able to contact this person at any time if they have questions. We expect participation in the education and counselling programme to be high $(>90 \%)$ and aim for full participation. At 2 weeks, 6 and 12 months after the training, the family is sent a questionnaire to assess their knowledge of diabetes in order to evaluate the effectiveness of the training programme (figure 1).
Staging and follow-up of children with multiple islet autoantibodies

An oral glucose tolerance test (OGTT) and an HbA1c test are performed in children with pre-type 1 diabetes within 6 weeks after the diagnosis of pre-type 1 diabetes to determine their level of glucose tolerance (normal, impaired or pathological). For all children, a monitoring plan is implemented at home and with their paediatrician. This includes visits to the diabetes centre every 1-6 month for measurement of random blood glucose, HbAlc, body weight and height. OGTTs are performed every 6-12 months depending on the child's glucose tolerance. $^{8}$ The families are provided with urine glucose sticks to monitor urine glucose every month, and a blood glucose metre and diary with instructions to measure blood glucose concentrations in children with impaired or pathological glucose tolerance.

In the event of pathological urine or blood glucose levels, the family is asked to immediately contact their local paediatric diabetes centre team. If hyperglycaemia $\left(\mathrm{ADA}\right.$ criteria $^{21}$ ) is diagnosed by the paediatrician, the child is immediately referred to the local paediatric diabetes centre team. All primary care paediatricians, the local paediatric diabetes centre team and the families are asked to record the following parameters and to inform us of the diagnosis at any time, including outside the setting of this project: symptoms (polyuria, polydipsia, polyphagia, weight loss), HbAlc, blood glucose levels (fasting, postprandial or 2-h OGTT level), blood gas analysis $\left(\mathrm{pH}\right.$ level, total $\mathrm{CO}_{2}, \mathrm{pCO}_{2}$, base deficit, base excess, potassium, sodium, chloride, blood urea nitrogen, plasma creatinine, $\beta$-hydroxybutyrate), urine ketones, duration of hospitalisation, intensive care requirements, and the date of starting insulin therapy.

\section{Stress assessment}

A repeatedly discussed risk associated with islet autoantibody screening is the potential psychological stress induced by a positive screening result, and the uncertainty regarding the child's future. If stress precedes the symptomatic manifestation of the disease by many years and impairs families' well-being severely over a longer period of time, it might offset the clinical benefits of an early diagnosis. Very few studies have assessed the psychological impact of islet autoantibody screening. Results of the BABYDIAB and TEDDY studies indicate that notification of a positive autoantibody test is associated with increased anxiety in parents that decreases over time (TEDDY unpublished data). ${ }^{22-25}$ We expect training and counselling to reduce psychological stress. The psychological impact, depression, anxiety and burden are monitored using a standardised questionnaire (Patient Health Questionnaire ${ }^{26}$ ) given on the diagnosis of pre-type 1 diabetes, and at 6 and 12 months later. Families with elevated anxiety and depression levels are referred for consultation to a local psychologist. The parents may also contact our free telephone hotline with any questions or concerns. 


\section{Statistical considerations}

Our estimate of the prevalence of pre-type 1 diabetes (multiple islet autoantibodies) is $0.3 \%$ (300 cases per 100000 screened children). This estimate is based on the expected prevalence of diabetes before the age of 20 years in Bavaria $(0.5 \%)$, and an expected sensitivity of multiple islet autoantibody positivity of $60 \%$ of these cases at $2-5$ years.

The feasibility and efficiency of the Fr1da study will be assessed in terms of the participation rates of screened children and children with multiple islet autoantibodies taking part in the education and counselling programme. The study will be considered successful if $>80000$ children participate in the screening, $>200$ children with pre-type 1 diabetes are identified over a period of 2 years, and if $>80 \%$ of positive children complete the education and counselling sessions. We expect that $>80 \%$ of the parents will be able to recall the most important symptoms of hyperglycaemia at 12 months after attending the educational programme. Rates of ketoacidosis or hospitalisation of $<5 \%$ within 12 months will be considered as indicators of success. Rates of ketoacidosis will be also compared to rates found in the Bavarian Register Cohort DiMelli. ${ }^{27}$

Statistical analyses will be performed on factors associated with pre-type 1 diabetes. Anticipating that 100000 children will be screened and 300 will be diagnosed with pre-type 1 diabetes, factors with an exposure rate of $30 \%$ (eg, caesarean section or factors categorised into tertiles) will have $80 \%$ power for an OR of $>1.4$ at a twotailed significance level of $5 \%$. Similarly, a factor with an exposure rate of $2 \%$ (eg, gluten or cereal introduction before 3 months of age) will have $80 \%$ power for an OR $>2.6$ at a two-tailed significance level of $5 \%$.

The impact of the diagnosis of pre-type 1 diabetes will be compared within participants over time (eg, using paired $\mathrm{t}$ tests) and with respect to a reference population at each time (eg, using two-sample $\mathrm{t}$ tests). Correlations between the family's knowledge of diabetes and the psychological impact at the same time will be determined to examine whether better knowledge of the disease and its treatment is associated with a lower psychological impact. We will also examine correlations with other relevant factors, such as parental education or age.

Data analysis will be performed using SAS (SAS Institute Inc., Cary, North Carolina, USA), R (http:// cran.r-project.org/), or SPSS (IBM Inc., Armonk, New York, USA). Missing data will be handled using elimination or imputation strategies, as appropriate. There are no interim analysis planned, except for a regular check of the current recruitment numbers. All other analyses will be performed in 2016 and 2017.

\section{RESULTS}

\section{Participation}

The Fr1da study started enrolment in February 2015. All 1027 primary care paediatricians in Bavaria were informed about the start of the Frlda study through a one-page letter and were invited to participate. Of these, 501 expressed interest and asked for more detailed information, and $404(39.3 \%)$ are currently enrolling children. As of 30 November 2015, 26760 children (13 713 males, 13047 females) have undergone screening tests. The weekly participation rate ranged from 135 to 1297 children, and it was affected by school holidays and by a postal strike in Germany which compromised sample shipment, but participation remained relatively constant (figure 2). There were no regional differences in the participation rates after considering the density of primary care paediatricians (figure 3). Overall, 3.6\% $(\mathrm{n}=962)$ of the children had a first degree relative with type 1 diabetes (table 1 ).

\section{Capillary blood collection}

Capillary blood samples were obtained for 26760 children, of which 25868 (96.7\%) contained sufficient
Figure 2 Numbers of children who underwent the islet autoantibody screening per week between February and November 2015.

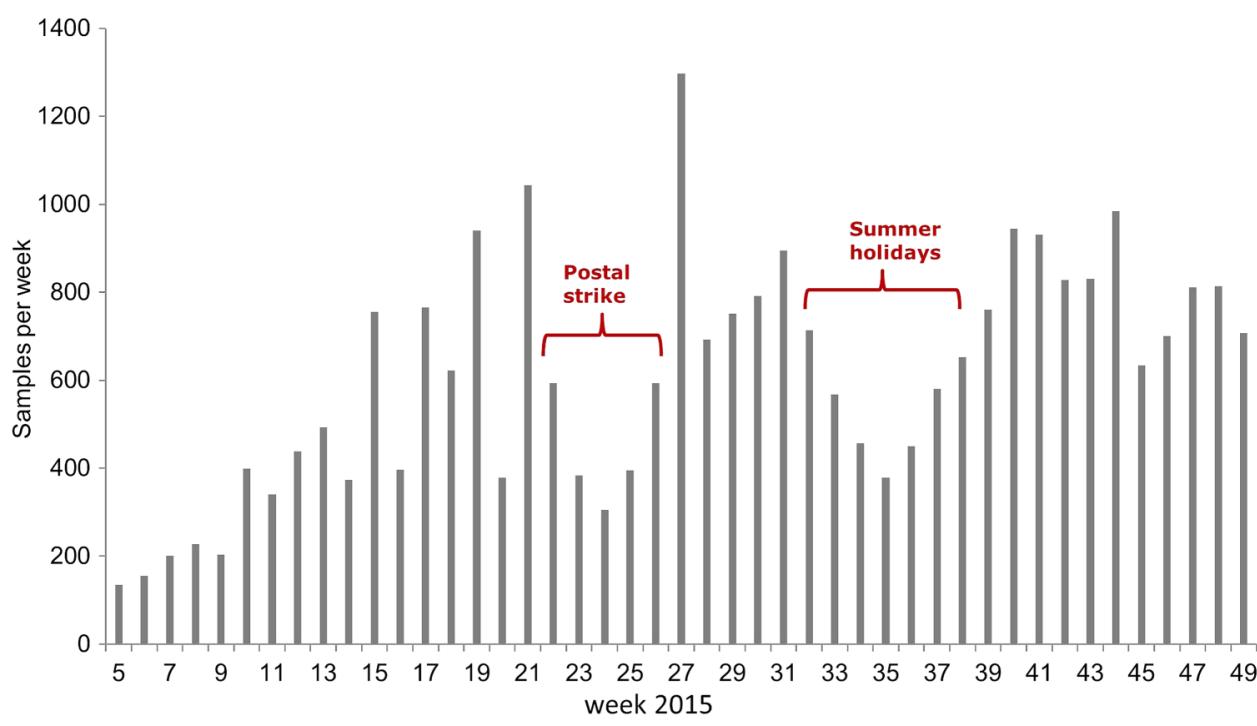


A

\% participating primary care pediatrician

avg. children per primary care pediatrician

B
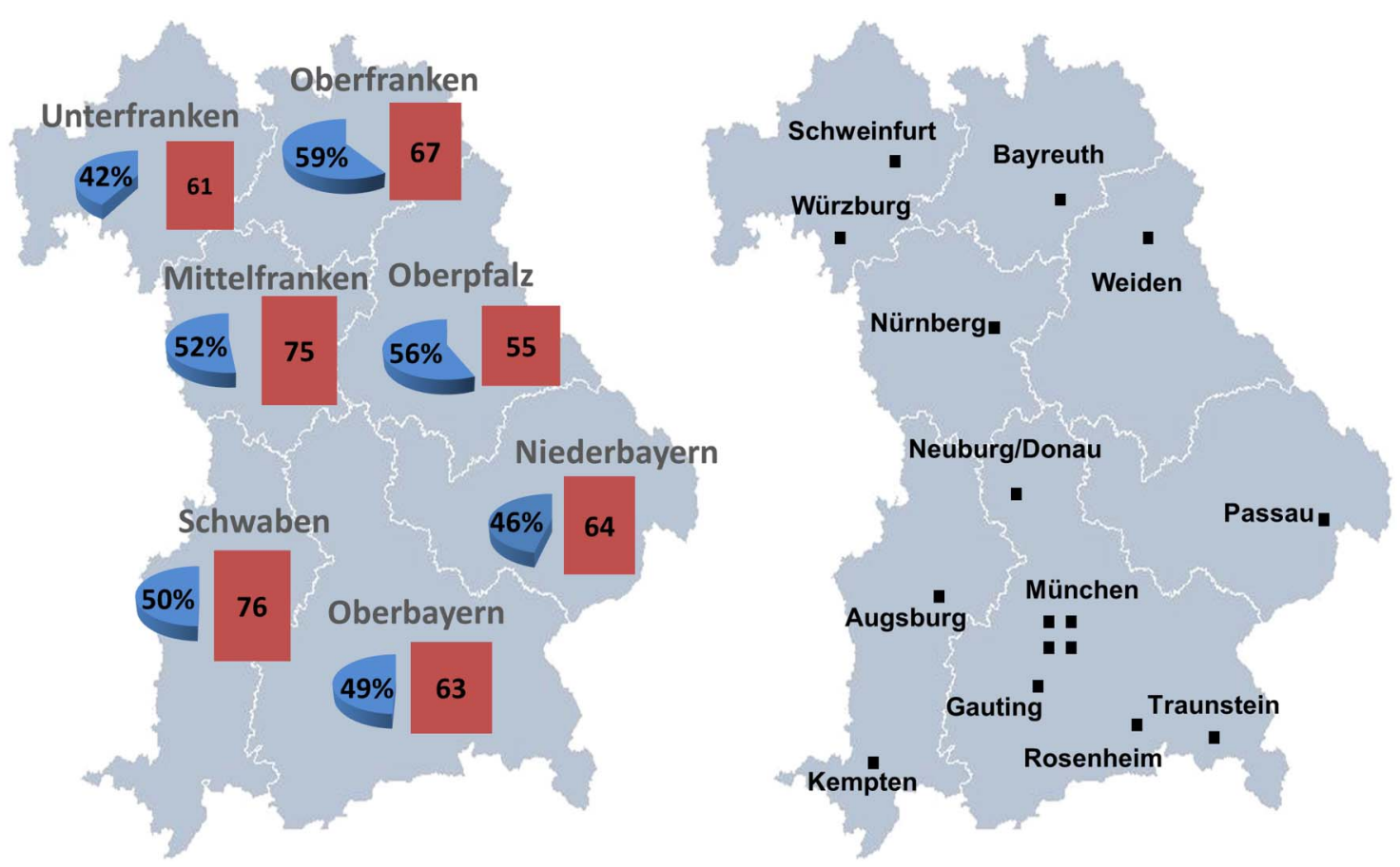

Figure 3 (A) Participation rates of primary care paediatricians per region in Bavaria (blue) and the mean number of children screened per primary care paediatrician (red). (B) Affiliated paediatric diabetes centre in Bavaria (black squares) following the children diagnosed with pre-type 1 diabetes. Children and families are offered an education and counselling programme following the diagnosis of pre-type 1 diabetes, glycaemic staging and psychological care related to the early diagnosis of diabetes.

volume to perform the three-screen ELISA islet autoantibody test. Of the remaining samples, $748(2.8 \%)$ were sufficient to perform the reference RBAs for GADA, IA-2A, and ZnT8A, and to enable the results to be communicated to the child's paediatrician. The other 144 $(0.54 \%)$ samples were too small and the paediatricians were asked to obtain a new sample; this was done for 48 children (table 1). Of all capillary samples received, $8912(33.3 \%)$ had visible traces of haemoglobin.

\section{Performance of RBA islet autoantibody detection in capillary blood}

Autoantibodies against GAD, IA-2, and ZnT8 correlated highly with capillary and venous blood of children (figure 4). The distribution of RBA islet autoantibodies was examined in Fr1da capillary blood samples that scored $<97.5$ th centile in the three-Screen ELISA results so as to determine whether venous serum thresholds for positivity were appropriate for capillary blood (figure 5). For GADA, IA-2A, and ZnT8A, the 99th centile previously defined in venous serum was very similar to the 99th centile of the capillary blood sample measurements. For IAA, there was a shift to higher assay signals if the capillary blood was visibly haemolysed. Moreover, the venous serum threshold of 1.5 units corresponded to the 97th centile of the non-haemolysed capillary blood samples. For comparison, we also examined the distribution of RBA values in capillary blood samples that were
$>97.5$ th centile in the three-Screen ELISA. At the venous serum established threshold, positive values were obtained in $25.2 \%$ for IAA in non-haemolysed samples, $13.6 \%$ for GADA, $7.7 \%$ for IA-2A, $8 \%$ for ZnT8WA and $7.7 \%$ for ZnT8RA.

\section{Prevalence of multiples islet autoantibodies and clinical type 1 diabetes}

Of the 26760 capillary samples tested, $105(0.39 \%)$ were positive for at least two islet autoantibodies, and a sample of venous blood was requested. To date, a second sample has been received from 77 children, of which $63(81.8 \%)$ were positive for multiple islet autoantibodies, and the diagnosis of pre-type 1 diabetes was communicated to the families (table 1). The multiple islet autoantibody status was not confirmed in 14 $(18.2 \%)$ children. Four children were diagnosed with clinical type 1 diabetes by collecting the capillary sample and the sample of venous blood.

\section{Participation rates in the education and counselling} programme, rate of ketoacidosis and psychological assessment

All families and their children with confirmed multiple islet autoantibodies (pre-type 1 diabetes) were invited to participate in the educational and counselling programme, and in metabolic OGTT staging. Two families refused to take part in these activities. The other 
Table 1 Characteristics of the study participants as of 30 November 2015

\begin{tabular}{ll}
\hline & $\begin{array}{l}\text { Number (\%) of } \\
\text { children/samples }\end{array}$ \\
\hline Screened children & $26760(13713$ males (51.2\%)) \\
Screened children with a first degree relative with type 1 diabetes & $962(3.6 \%)$ \\
Samples with a sufficient volume to perform the 3-screen ELISA & $25868(96.7 \%)$ \\
Samples with insufficient volume for the 3-screen ELISA but sufficient for the RBA & $748(2.8 \%)$ \\
Samples with insufficient volume for the 3-screen ELISA or the RBA prompting a & $144(0.54 \%)$ \\
request for a new sample & 48 \\
Sample obtained again and sent to the centre & $105(0.39 \%)$ \\
Children with multiple islet autoantibodies detected in the first sample & 63 \\
Children with confirmed multiple islet autoantibodies (ie, pre-type 1 diabetes) & 4 \\
Children diagnosed with asymptomatic type 1 diabetes between the first and & 14 \\
second sample & 24 \\
Children without confirmation of multiple islet autoantibodies & \\
Children pending confirmation & \\
\hline RBA, radiobinding assay. &
\end{tabular}

families have either completed OGTT staging and participated in the education and counselling programme at 1 of 16 affiliated paediatric diabetes centres in Bavaria, or are scheduled to participate in these within 6 weeks.

Based on the OGTT results, $89 \%$ children were normoglycaemic, 9\% had impaired glucose tolerance, and $2 \%$ had pathological glucose tolerance (clinical type 1 diabetes). Children with normoglycaemia were asked to measure their urine glucose every month, and all of them adhered to the regular measurements until today and have submitted their results (see figure 2 of ref. 8). Children with impaired glucose tolerance were asked to measure blood glucose every week, and all of them adhered to the measurements and submitted their results. Children with pathological glucose tolerance were asked to measure their blood glucose every day, and none have started insulin therapy to date. One child with impaired glucose tolerance has progressed to hyperglycaemia to date. None of the children tested in the Fr1da study had ketoacidosis. The psychological assessment revealed no serious distress in any of the families that needed immediate reaction and treatment. Analyses of parent's well-being at the time of early diagnosis revealed symptoms of anxiety and depression in $1.5 \%$ of parents which is comparable to the German norm population.

\section{DISCUSSION AND SIGNIFICANCE}

The Frlda study is a population-based study that was implemented to examine the feasibility of early diagnosis of type 1 diabetes by islet autoantibody screening in infants, without preselecting the target population in terms of genetic susceptibility or family history. This study, as a model project, has demonstrated the feasibility of collaborating with primary care paediatricians and the introduction of a public health screening test within the context of regular compulsory checkups, followed by education, counselling, and follow-up assessments.
Over 10 months, a mean of 2676 children have been screened every month. This is considerably higher than previous screening programmes in school children, where 200-400 children per month underwent venipuncture. ${ }^{28-31}$ The single capillary blood sampling procedure was efficient, and provided sufficient volume for the diagnosis of pre-type 1 diabetes in nearly $99.5 \%$ of children. Moreover, we have established that capillary blood samples can be used for screening purposes. Overall, $0.39 \%$ of children were positive for multiple islet autoantibodies in the first capillary blood screening, and we estimate that in approximately another $0.3 \%$ of children this will be confirmed by a second venous sample; however, the numbers of children with confirmed samples are still very small.

Participation rates in the education, counselling, and follow-up assessment were very high. This is encouraging because education of pre-type 1 diabetes is a novel concept that has not been previously explored. We expect that this tailored education will prevent children from acquiring diabetic ketoacidosis and families' from psychological distress.

To date, none of the children in the Frlda study have been diagnosed with ketoacidosis. This finding may be due to the screening programme and/or an increased awareness of type 1 diabetes among paediatricians. Approximately 900 children suffer from life-threatening ketoacidosis at diabetes onset in Germany each year, corresponding to about one-third of all children with newly diagnosed type 1 diabetes. ${ }^{32}$ Ketoacidosis at the onset of type 1 diabetes is associated with increased mortality and longer hospitalisation, translating into increased cost and is less likely to be associated with partial remission in the first year after diagnosis and after 2 years of symptomatic disease. It is also associated with lower residual $\beta$ cell function, worse metabolic control, and higher insulin requirements. ${ }^{33}{ }^{34}$ Previous studies have shown that the prevalence of diabetic ketoacidosis, HbAlc, and the length of hospitalisation were considerably lower in 

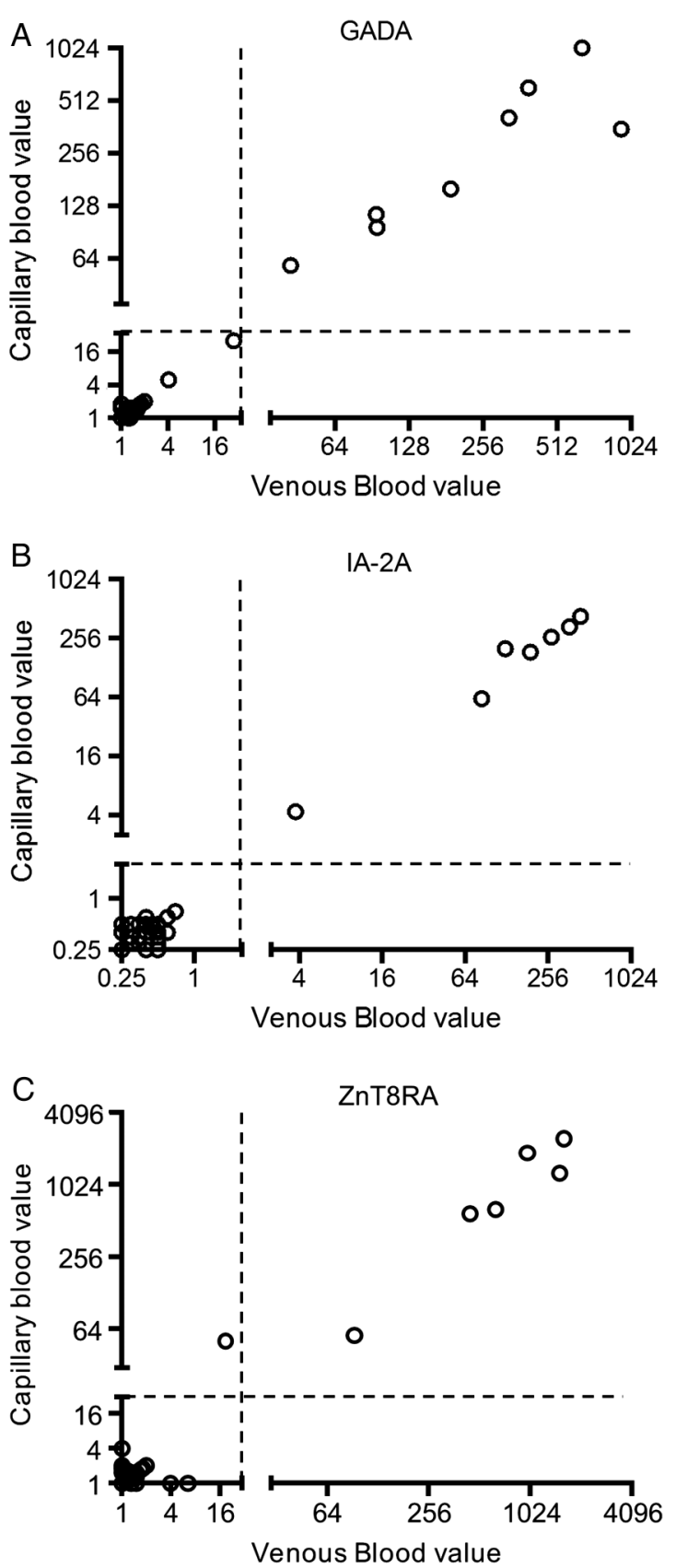

Figure 4 Correlation between capillary and venous blood levels of antibodies against GAD, IA-2, and ZnT8 in 31 children (GADA: $R^{2}$ 0.69, $p<0.0001$; IA-2A R ${ }^{2} 0.98, p<0.0001$; ZnT8RA: $\left.R^{2} 0.89, p<0.0001\right)$. GAD, glutamic acid decarboxylase; GADA, glutamic acid decarboxylase autoantibodies.

children diagnosed at an early stage via islet autoantibody screening. 453536

Limitations of the Fr1da study design include the fact that we do not follow children with single islet autoantibodies. A minority of these children will develop diabetes. A second limitation with respect to sensitivity is the cross-sectional screening at one single time point. Repeated screening at a later age is costly, but will increase the sensitivity of the approach. A third limitation is that our study design does not address the socioeconomic aspect of introducing such a screening for the prevention of diabetic ketoacidosis and its complications. While costs and benefits will differ between different healthcare systems and the worth of saving lives debated, it still will be important to formally address the economics of the prevention of DKA or type 1 diabetes. $^{37}$

In conclusion, the Frlda study, if successful, could have a major impact on the implementation of screening for pre-type 1 diabetes in the preventive health programme in Germany, and potentially other countries. The study uses validated assays and a clear strategy for identifying children with multiple islet autoantibodies so as to help prevent diabetic ketoacidosis at a population level, thus reducing the family's burden and potentially healthcare costs. We also expect to set new standards for the early diagnosis of type 1 diabetes, as well as provide subsequent education and counselling for children diagnosed with pre-type 1 diabetes. Furthermore, the Fr1da study will provide us with the opportunity to assess the impact of environmental exposures on pre-type 1 diabetes since a population-based approach is most suitable for such analyses. These exposures include air pollution, population density and drinking water quality data which are available for Bavaria and have not been examined in other natural history studies. Moreover, the study will provide an unprecedented opportunity to design secondary prevention studies to delay or prevent the onset of hyperglycaemia and insulin dependence at a population-based level, and will implement this with a relatively rapid recruitment capacity.

\section{ETHICS AND DISSEMINATION}

The study was approved by the ethics committee of Technische Universität München (Nr. 70/14). An information sheet is given to the parents or the legal guardians, in person, by the child's paediatrician. The child's representative is given sufficient time to read the information sheet and the opportunity to ask any questions before completing the consent form. The parents or legal guardians are informed that participation in the study is voluntary and that consent can be withdrawn at any time, without giving a reason and without any disadvantages. All data will be treated confidentially, and data will be protected throughout the study in accordance with relevant laws. The findings of the study will be disseminated through peer-reviewed journals, national and international conference presentations, and to the paediatricians via regular newsletters.

\section{STUDY ORGANISATION}

The Frlda study is organised by the Institute of Diabetes Research, Helmholtz Zentrum München and Forschergruppe Diabetes, Klinikum rechts der Isar, Technische Universität München, where the screening centre is located. The screening centre includes study coordination, data and logistic coordination, the central 

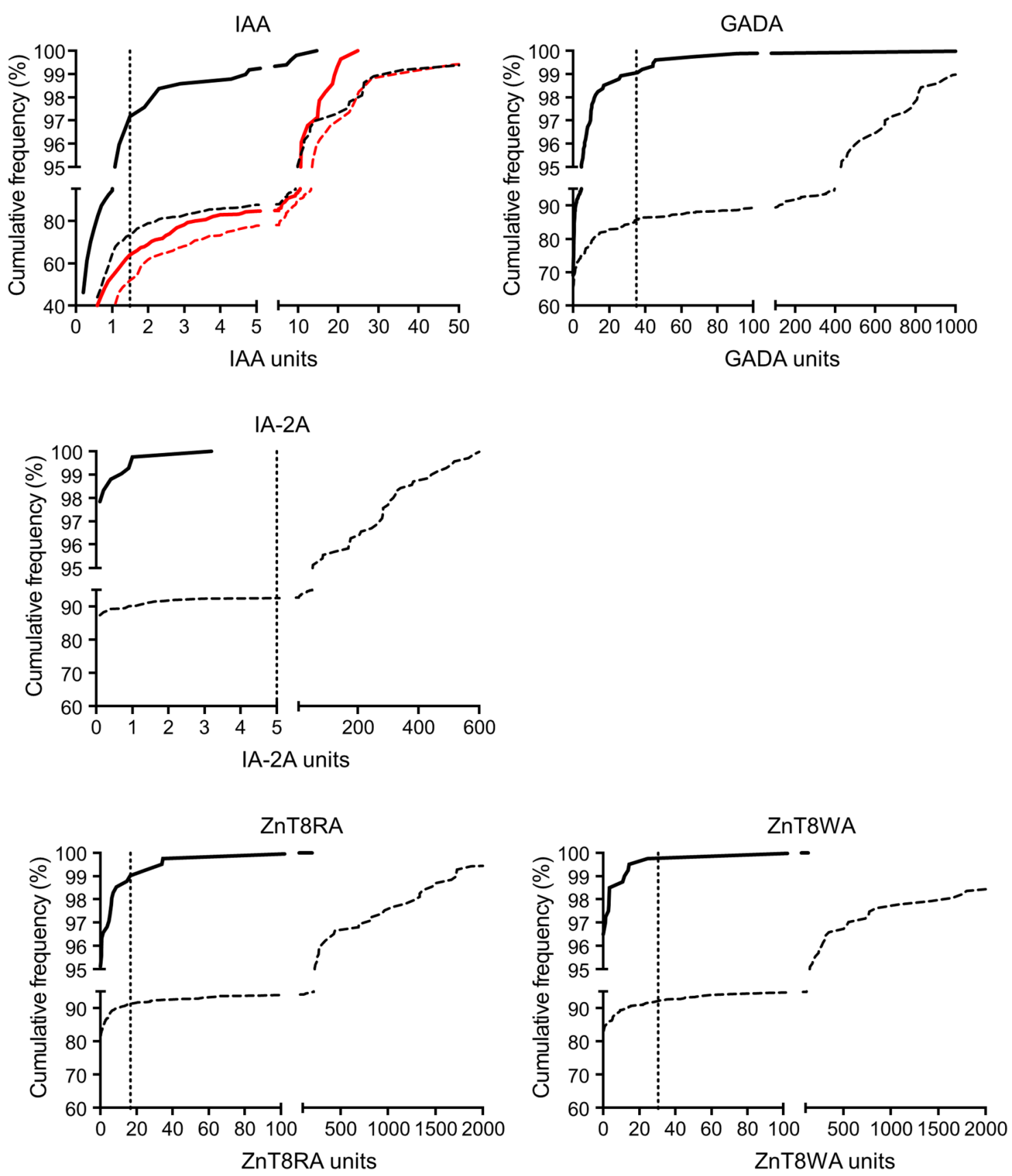

Figure 5 Cumulative frequency distribution of RBA values for islet autoantibody measurements in capillary blood samples. For each islet autoantibody, RBA values ( $x$ axis) are plotted against the percentage of samples having equal or lower values (y axis). Shown are samples that were $<97.5$ centile in $3-S c r e e n$ ELISA (solid lines; $n=409$ ) and samples that were $>97.5$ centile in 3Screen ELISA (broken lines, $n=568$ ). For IAA, the distributions are shown for samples that were visibly haemolysed (red lines) and non-haemolysed (black). The dotted lines represent the thresholds of positivity established for venous blood.

laboratory, public relations and statistical analysis. The study is performed in collaboration with primary care paediatricians (Berufsverband der Kinder und Jugendärzte e. V., Landesverband Bayern and PaedNetz) in Bavaria who perform the screening, and the affiliated paediatric diabetes centres which conduct the education programme (see below) and the psychology team (see below) responsible for the psychological assessment of the study. The Frlda study is being conducted in cooperation with the Bayerisches Landesamt für Gesundheit und Lebensmittelsicherheit and the Bayerisches Staatsministerium für Gesundheit und Pflege (under the auspices of Melanie Huml, MdL).

\section{Author affiliations}

${ }^{1}$ Institute of Diabetes Research, Helmholtz Zentrum München, and Forschergruppe Diabetes, Klinikum rechts der Isar, Technische Universität München, Neuherberg, Germany

${ }^{2}$ Forschergruppe Diabetes e.V., Neuherberg, Germany

${ }^{3}$ Department of Pediatrics, Klinikum rechts der Isar, Technische Universität München, München, Germany 
${ }^{4}$ Department of Medical Psychology, Hannover Medical School, Hannover, Germany

${ }^{5}$ Bavarian Health and Food Safety Authority, Oberschleißheim, Germany ${ }^{6}$ Berufsverband der Kinder- und Jugendärzte e.V., Landesverband Bayern, Augsburg, Germany

${ }^{7}$ PaedNetz Bayern e.V., Rosenheim, Germany

${ }^{8}$ Klinikum Augsburg, Klinik für Kinder und Jugendliche, Augsburg, Germany ${ }^{9}$ Centre for Regenerative Therapies Dresden, Faculty of Medicine, Technische Universität, Dresden, Germany

${ }^{10}$ Paul Langerhans Institute Dresden of Helmholtz Centre Munich at University Clinic Carl Gustav Carus of Technische Universität, Dresden, Germany

\section{Collaborators Fr1da Study Group: Screening centre-Members and roles of} the central organising team at the Institute of Diabetes Research, Helmholtz Zentrum München-Principle investigator: Anette-G. Ziegler. Study coordination: Jennifer Raab, Florian Haupt, Christiane Winkler, and Robin Assfalg. Logistics and database management. Florian Haupt. Islet autoantibody determination, sample processing, and methodology development: Peter Achenbach, Ezio Bonifacio, Susanne Wittich, Katharina Weininger, Marlon Scholz, Claudia Matzke, Stephanie Riethausen, Lisa Schneider, and Rainer Fürst. Teaching, care, and follow-up of children with pre-type 1 diabetes: Stephanie Zillmer, Katharina Warncke, Stephanie Löbner, Annette Knopff, Elisabeth Strauss, Joanna Stock, and Claudia Ramminger. Data analysis: Andreas Beyerlein, Ezio Bonifacio, and Peter Achenbach. Public relations: Cordula Falk. Administrative and Scientific Management: Ramona Puff. Dissemination, information, and public relations: Sonja Optiz, Ulrike Koller, and Helge Siemens (Corporate Communications Department, Helmholtz Zentrum München). Psychology team - Karin Lange and Iris Müller (Department of Medical Psychology, Hannover Medical School, Hannover Germany). Primary care paediatricians - Renate Abt, MD, Wendelstein; Aderbauer/Leonhardt/Riedl, MD, Weiden; Ina Albrich, Dorfen; Stephan Arenz, MD, Pfaffenhofen; Bernd Aulinger, MD, Burglengenfeld; Glenn Averbeck, MD, Pfaffenhofen; Annette Bachmann-Hoschka, MD, Teisendorf; Andrea Bachmeyr, MD, München; Baier/Baier, MD, Schwabach; Elmar Barthel, MD, Gemünden; Marina Bascone-Fricke, MD, Aidenbach; Batz/Hubmann, MD, Zirndorf; Rolf Bauer, MD, Roth; Yvonna Bauer, MD, Augsburg; Gunhild Bauer-Niedermaier, MD, Zirndorf; Larissa Baumgärtner, Heilsbronn; Michael Bäzner, MD, Sonthofen; Beck/Baier/Mussar, MD, Donauwörth; Axel Becker, MD, Haar; Beer/Schirmer, MD, Marktredwitz; Lutz Bellingrath, MD, Bamberg; Reiner Benckendorff, MD, Augsburg; Gertraud Bergen, MD, Haßfurt; Monika Berger, MD, Haimhausen; Annerose Bergner, MD, München; Beste/Hosemann, MD, Dachau; Reinhard Beuthan, MD, Dingolfing; Katrin Biebach, MD, München; Dominique Bienert, MD, München; Matthias Bierler, MD, Amberg; Biermann-Franke/Trinczek, MD, Erlangen; Klaus Binder, MD, Nürnberg; Brigitte Birk, MD, Peißenberg; Maria-Magdalena Blauditschek, MD, Würzburg; Jörg Blume, Schweinfurt; Blümel-Eiber/Rösch, MD, Nürnberg; Andreas Blüml, Trostberg; Sabine Böhm-Vogt, MD, Ottobrunn; Karola Börzsönyi, MD, Freising; Stephan Böse-0'Reilly, MD, München; Malte Bräutigam, MD, Eichstätt; Walter Breiner, Marktoberdorf; Ulrike Brendel, MD, Parsberg; Michael Brijnen von Oldershausen, MD, München; Christian Brückmann, MD, Brannenburg; Halina Eva Buchalik, Lauf an der Pegnitz; Franz Bundscherer, MD, Geretsried; Anna Bürcky, MD, Ochsenfurt; Barbara Capelle, MD, Unterhaching; Mona Castrop, MD, Regensburg; Alina Cocos, MD, Markt Schwaben; Cordes/Gebhard, MD, Nürnberg; Christoph Daffner, MD, Nürnberg; Arcan Demircioglu, MD, München; Jost Dieckerhoff, MD, Rosenheim; Karolin Diergarten, MD, Germering; Elmar Dietmair, MD, Bobingen; Lutz Dietrich, MD, Hof; Maximilian Dietrich, MD, Aichach; Brigitte Dietz, MD, Taufkirchen; Christian Döbig, MD, Erlangen; Sylvia Döpfer, MD, München; Jürgen Dörrer, Freyung; Ragnar Dörrfuss, MD, Nürnberg; Monika Drexel, MD, Rehau; Elke Düll-Schiller, MD, Neumarkt; Stefan Eber, MD, München; Christoph Ebert, MD, Ebersberg; Thomas Ebert, Veitsbronn/Siegelsdorf; Christina Eder, MD, Bayreuth; Claudia Eichwald, MD, Ingolstadt; Annette Eiden, MD, Gauting; Claus Engelhardt, MD, Nürnberg; Anja Engelmann, MD, Dinkelscherben; Georg Engl, MD, München; Uta Enzensberger, MD, Mering; Patricia Erlinger, MD, Postbauer-Heng; Uwe Ermer, MD, Neuburg/Donau; Kirsten ExI, München; Florian Fackler, MD, Erlangen; Edgar Fath, MD, München; Peter Feiereisen, MD, München; Daniela Felsl, MD, Wolnzach; Fendel/Wieland, MD, München; Maria Fischer, MD, Lappersdorf; Cordula Fischer-Trüstedt, MD,
München; Katrin Franke-Augustin, MD, Bayreuth; Harald Frantzmann, MD, Memmingen; Rudolf Franz, MD, München; Claudia Frey, MD, Augsburg; Susanne Gandenberger, MD, München; Antonia Gavazzeni, MD, München; Christian Geißendörfer, MD, Selb; Edeltraud Gerber, MD, Kolbermoor; Martin Gerlich, MD, Dinkelsbühl; Elke Gerlitz, MD, Herzogenaurach; Julia Gerstl, MD, Hauzenberg; Jürgen Geuder, MD, Freilassing; Johannes Gilles, Gunzenhausen; Rainer Gillessen, MD, Ottobrunn; Cornelia Gläßel, MD, Fürth; Judith Glöckner-Pagel, MD, Regensburg; Hermann Gloning, MD, München; Birgit Goldschmitt-Wuttge, MD, München; Martin Götz, MD, Elisabethzell; Wolfgang Graser, MD, Nürnberg; Marion Grau-vom-Scheidt, MD, Nürnberg; Martin Griebel, MD, Poing; Angelika Gruber-Müller, MD, Ingolstadt; Dietrich Grunert, MD, Kempten; Christian Haas, MD, München; Richard Haaser, MD, Feucht; Caroline Haberl, MD, Starnberg; Ulrich Hagen, MD, Friedberg; Verner Hallmen, MD, München; Emma Halwas, MD, Geisenfeld; Ingrid Hartmann, MD, Lichtenfels; Conny Hartmann, MD, Bad Wörishofen; Christian Hartnik Bad Staffelstein; Ulrike Haun, MD, Vilshofen; Gabi Haus, MD, München; Rudolf Havla, MD, Hof; Wolfgang Heck, MD, Vöhringen; Heck-Buchhorn/ Willnow, MD, Kösching; Ralph Heidingsfelder, Ansbach; Anette Hein, MD, Gerbrunn; Markus Helmreich, MD, Schweinfurt; Tanja Hemmers, MD, Augsburg; Anna Hencz, MD, Germering; Holger Hertzberg, MD, Schwabach; Sigrid Hesse, MD, Straubing; Daniela Heuschmann, MD, Regensburg; Cornelia Hoegen, MD, Herrsching; Reinhard Hoffmann, MD, Landshut; Steffen Hoffmann-Baldus, MD, Haar; Gerhard Hofmann, MD, Würzburg; Meike Hofmann, Mitterteich; Sabina Hohn, Nürnberg; Gabriele Hopf, MD, Ingolstadt; Jörg Horcher, MD, Straubing; Birgit Hortig-Nevelö, MD, Regenstauf; Annette Hovestadt, MD, München; Irene Hummel, Bamberg; Peter Hußlein, MD, Grassau; Wolfgang Hüttner, MD, Coburg; Anna larrapino-Demmel, MD, München; Birgit Indlekofer, MD, Tutzing; Annelie Intemann, MD, München; Margarete Jäger, MD, München; Peter Jakob, MD, Erlangen; Christine Janello, MD, Neubiberg; Jarosch/Schleupner, MD, Würzburg; Stefan Jobst, MD, Bayreuth; Janina Joiko, MD, München; Guido Judex, Regensburg; Ronny Jung, MD, Roth; Andreas Kalmutzki, Schwabach; Lampros Kampouridis, MD, Baldham; Michael Kandler, MD, Nürnberg; Susanne Kastl, MD, Bayreuth; Walther Kaufmann, Nürnberg; Bernhard Keck, MD, Augsburg; Peter Kellner, MD, Vilsbiburg; Lars Kellner, MD, Gräfelfing; Ghassan Khazim, MD, Hammelburg; Conelia Kiani, MD, Bayreuth; Gunhild Kilian-Kornell, MD, Starnberg; Annegret Klein, MD, Oberaudorf; Wolfgang Klein, MD, Augsburg; Kristina Klemp, MD, Burgkunstadt; Margreth Knebel, MD, München; Norbert Knieß, MD, Ingolstadt; Kober/Spannagel, MD, Gmund; Cornelia Komm, MD, Waldkraiburg; Nikos Konstantopoulos, MD, München; Cosima Köring, MD, Altötting; Renate Kramer, MD, München; Guido Krandick, MD, Deisenhofen; Barbara Krappatsch, MD, Viechtach; Krebs/Güler, MD, Neuendettelsau; Berndt Kreisberger, MD, Ismaning; Gerlinde Kreß-Rohrbach, MD, Stegaurach; Josef Kriesmair, MD, München; Andreas Kronwitter, MD, München; Matthias Krueger, MD, Klingenberg; Kubryk/Döring, MD, Aschheim; Thomas Kuchenbauer, MD, München; Ursula Kuhnle-Krahl, MD, Gauting; Stephan Küntzer, MD, Kitzingen; Wolfgang Künzer, MD, Regensburg; Beate Kusser, MD, München; Werner Küstermann, MD, Veitshöchheim; Wolfgang Küver, MD, München; Franz Lachner, MD, Ruhpolding; Wolfgang Landendörfer, MD, Nürnberg; Christina Lang, MD, Nürnberg; Martin Lang, MD, Schwabmünchen; Martin Lang, MD, Augsburg; Lang/Zötl, MD, Bad Tölz; Otto Laub, Rosenheim; Peter Lautenbach, Herzogenaurach; Gerhard Legat, MD, Amberg; Karl-Heinz Leppik, MD, Erlangen; Katrin Leuchtenberger, MD, Kelheim; Karin Leykauf, Bayreuth; Hans Lichtenstern, MD, Pocking; Werner Lick, MD, Würzburg; Gabriele Lieb, MD, Würzburg; Bärbel Liebezeit, MD, Mühldorf am Inn; Armin Liebscher, MD, Eckental; Susanne Linder, MD, Grafrath; Ruth Lindner-Gajek, MD, München; Lipinski/ Mende/Kirtscher, MD, Lindenberg; Harald Lodes, MD, Neumarkt; Markus Loeff, MD, Landsberg am Lech; Andreas Lorenz, Krumbach; Martin Löw, Memmingen; Anna Elisabeth Lüdtke, MD, Neu-UIm; Renata Lysy, MD, Möhrendorf; Eva Maas-Doyle, MD, Erlangen-Tennenlohe; Michaela Maier, MD, Pfaffenhofen; Soyoun Maisch, MD, München; Stefanie Marr, Ingolstadt; Martin/Schilder, MD, Schrobenhausen; Stephan Martini, MD, München; Monika Maurus, MD, Memmingen; Barbara Meiler, Grafrath; Bettina Meinel, MD, Regensburg; Udo Meißner, MD, Bamberg; Steffi Menzel, München; Jürgen Messner, MD, Lohr; Roland Metzner, MD, Würzburg; Petra Sibyl Meyer, MD, Augsburg; Oliver Michael, Murnau; Rupert Moser, Schwandorf; Kathrin Mothes, MD, Schwandorf; Miriam Mrach, München; Sabine Mühlbauer, MD, München; Ulrich Müller, MD, München; Herbert Müller, MD, Kempten; Müller/ Wilken/Schürmann, MD, Naila; Müller/Wilken/ 
Schürmann, MD, Hof; Patrick Muzzolini, MD, Kulmbach; Sabine Nagel, MD, Neustadt/Do.; Dieter Nagel, MD, Freyung; Karsten Naumann, Erlangen; Nicole Nellen-Hellmuth, MD, Würzburg; Klaus Neumann, MD,

Höhenkirchen-Siegertsbrunn; Christiane Neumeir, MD, Königsbrunn; Hans-Peter Niedermeier, MD, Erding; Jochen Noss, MD, München; Andreas Nowack, MD, Siegsdorf; Thomas Nowotny, MD, Stephanskirchen; Stefan Oberle, MD, Höchstadt; Osang/Pudenz, MD, München; Nicola Pape-Feußner, MD, Berg; Parhofer/Wiß, MD, Dachau; Michael Pätzold, Marktoberdorf; Christian Pauli, MD, Olching; Michaela Pausenberger, MD, Lauf a.d. Pegnitz; Angela Pfeffer, MD, Regen; Bergit Pfleger, Neuendettelsau; Stefan Platzer, MD, Osterhofen; Hermann Pöhlmann, Bayreuth; Polster/Kainzinger, MD, Dingolfing; Pontz/Wimmer, MD, Passau; Manfred Praun, MD, Gilching; Preis/ Preis, MD, Bischberg; Preissler/Tomas/Theil, MD, Gersthofen; Verena Printz, MD, Fürstenfeldbruck; Prinz/Sedlacek, MD, Burgau; Barbara Przyklenk, MD, München; Georg Puchner, MD, Regensburg; Marco Ramella Pezza, MD, Meitingen; Rampf/Lautner, MD, Freising; Jürgen Ratay, MD, Freising; Thomas Rath, MD, Landsberg am Lech; Karla Rauschning-Sikora, MD, Mainaschaff; Christiane Razeghi, MD, Miesbach; Anja Regenfus, MD, Nürnberg; Brigitte Reichstein, MD, Ingolstadt; Reitz/Pawlak, MD, Rosenheim; Christian Renner, MD, Deggendorf; Renz/Lauterbach, MD, Weiden; Tobias Reploh, MD, Bad Tölz; Reschke/Exner, MD, Kaufbeuren; Michael Richter, MD, München; Mustafa Rihawi, MD, Kronach; Ringert-Esmaeili/Müller-Bühl, MD, Alzenau; Carsten Rinker, MD, München; Ingrid Rohland, MD, Erding; Herbert Rohr, MD, Fürstenfeldbruck; Alexander Roithmaier, MD, München; Rosenthal/ Lütkemeyer, MD, Unterschleißheim; Anne Katrin Rothe, MD, München; Irene Rühlemann, MD, München; Ramon Rümler, MD, Dachau; Monika Sachse, Neumarkt/Opf.; Uwe Sack, MD, Würzburg; Sirin Salik, Nürnberg; Schaaff/ Höpner, MD, Eckental-Eschenau; Hans-G. Schatz, MD, Bayreuth; Hans-Ulrich Schatz, MD, München; Carolus Schenke, MD, Neustadt a.d. Aisch; Barbara Scherer, MD, München; Scheuerer/Eidenschink, MD, München; Ute Schindler, MD, Kelheim; Lydia Schlak, Sulzbach-Rosenberg; Andreas Schlossbauer, Bad Kissingen; Schmid-Seibold/Leipold, MD, Regensburg; Volker Schmidt, MD, Kempten; Stefan Schmidt, Rosenheim; Dorothea Schmidt-Colberg, MD, Erlangen; Stephan Schneider, Schweinfurt; Klaus Schnell, MD, Coburg; Scholz/Scholz-Kühn, MD, Deggendorf; Monika Schömig-Spingler, MD, Würzburg; Volker Schönecker, Kaufering; Martin Schöniger, MD, Weilheim; Philipp Schoof, München; Franziskus Schuhböck, MD, Kirchheim; Christine Schweikl, MD, Eggenfelden; Rosemarie Schwertner, MD, Germering; Christian Seidel, MD, Ingolstadt; Josef Seidl, MD, Füssen; Monika Seidt, MD, München; Seiler/Pletl-Maar, MD, Erlangen; Horst Seithe, MD, Nürnberg; Marko Senjor, MD, Wasserburg am Inn; Manfred Singer, MD, Forchheim; Wilfried Späth, Weißenhorn; Michael Sperlich, MD, Ampfing; Spieß/Robert, MD, Neuburg; Spooren/Usadel, MD, Senden; Sprich/Sannig, MD, Biessenhofen; Johannes Stadler, Gerolzhofen; Wilhelm Stechl, MD, Raubling; Wolfgang Steck, MD, Immenstadt; Constanze Steinborn, MD, Sauerlach; Bernd Steinkirchner, MD, Neufahrn; Stefan Stellwag, MD, München; Frank Steppberger, Oberasbach; Anke Steuerer, MD, Augsburg; Stöckhert/Meyer, MD, Fürth; Christoph Stöhr-Sökefeld, MD, Neubiberg; Annette Stratmann, MD, Holzkirchen; Dominik Stricker, MD, Lappersdorf; Annette Strobel, MD, Erlangen; Michael Strobelt, MD, Bruckmühl; Gesine Strohbach, Nürnberg; Thomas Sturm, MD, Fürstenfeldbruck; Raphael Sturm, MD, Affing; Sturm/Mayr, MD, Memmingen; Vita Teichler, MD, München; Günter Theurer, MD, Traunstein; Uta Tielker, MD, Eichenau; Achim Timnik, MD, Neusäß; Michael Torbahn, MD, Nürnberg; Regina Trammer, MD, Planegg; German Tretter, MD, Altenstdt/WN; Burkhard Trusen, MD, Bamberg; Roland UImer, MD, Lauf; Stephan Unkelbach, MD, Volkach; Reiner Valentin, MD, Grafing; Michael Veh-Hölzlein, Fürth; Veh-Hölzlein/Richter, MD, Fürth; Oliver Viethen, MD, Traunstein; Michael Vogel, MD, München; Victor von Arnim, MD, Roding; Eleonore von der Schulenburg, MD, München; Patrik von Schoenaich, MD, Neusäss; Olaf Vorbeck, Moosburg; Christoph Wachenfeld-Wahl, MD, Augsburg; Roland Wagner, MD, Nittendorf; Edgar Waldmann, MD, Bamberg; Karin Waldmann, Memmelsdorf; Annette Weber-Pöhlmann, MD, Selb; Claudia Wegener, MD, München; Josef Weidinger, MD, Nabburg; Johannes Weigel, MD, Augsburg; Weigel/Chittka/Kordowich, MD, Karlstadt; Christine Weigmann-Popp, MD, Bamberg; Benedikt Weiß, MD, Bad Kötzting; Mathias Wendeborn, MD, München; Wiesheu/Buckl/Paul/Popp, MD, Landshut; Wiessner-Straßer/ Eisenhut, MD, München; Hermann Wittrock, Mering; Daniela Wohlmann, MD, Garmisch-Partenkirchen; Alexander Zeiss, MD, München; Roland Zeller, Aschaffenburg; Stefan Zeller, MD, Kempten; Ziemer/Ziemer, MD, Nürnberg;
Ulrich Zimmer, MD, Rothenburg ob der Tauber; Mathias Zimmer, Coburg; Lothar Zimmermann, MD, Aichach; Thomas Zimmermann, MD, Burgebrach; Thomas Zimmermann, MD, Hirschaid; Andreas Zurmühl, MD, Penzberg; Kristin Zwenzner, MD, Neudrossenfeld; Affiliated Diabetes CentresEngelsberger, MD, Katharina Warncke, MD, Kinderklinik Schwabing, Desiree Dunstheimer, MD, Klinikum Augsburg; Horst Seithe, MD, Klinikum Nürnberg Süd; Eva-Maria Gerstl, MD, Klinikum Dritter Orden Passau; Herbert Müller, MD, Klinikum Kempten; Reinhard Koch, MD, Leopoldina Krankenhaus Schweinfurt; Christian Ockert, MD, RoMed Klinikum Rosenheim; Stefanie Tretter, MD, Klinikum Weiden; Ursula Kuhnle-Krahl, MD, Gauting; Nicole Nellen-Hellmuth, MD, Würzburg; Uwe Ermer, MD, Kliniken St. Elisabeth Neuburg/Donau; Susanne Bechtold-Dalla Pozza, MD, Haunersches Kinderspital München; Antonia Gavazzeni, MD, München; Silke Christina Schmidt, MD, Klinikum Dritter Orden München; Marina Sindichakis, MD, Klinikum Traunstein; and Sonja Braig, MD, Klinikum Bayreuth.

Contributors AGZ, EB, PA, CW, JR, and FH designed the study and drafted the manuscript. $A B$ and $E B$ developed the statistical methods and wrote the statistical section of the protocol. MS, CM, KW, KL, RA, KW, SW, SL, DD, $\mathrm{UN}-\mathrm{R}, \mathrm{ML}$ and $\mathrm{OL}$ contributed to the design of the study and reviewed the manuscript for intellectual content.

Funding The Fr1da study is supported by grants from the LifeScience-Stiftung, JDRF (1-SRA-2014-310-M-R), the Bavarian State Ministry of Health and Care (Gesund.Leben.Bayern, LP00228), Deutsche Diabetes-Stiftung, Landesverband Bayern der Betriebskrankenkassen, B. Braun-Stiftung (BBST-D-15-00016), and Deutsche Diabetes-Hilfe.

Competing interests None declared.

Patient consent Obtained.

Ethics approval The study was approved by the ethics committee of Technische Universität München (Nr. 70/14).

Provenance and peer review Not commissioned; externally peer reviewed.

Open Access This is an Open Access article distributed in accordance with the Creative Commons Attribution Non Commercial (CC BY-NC 4.0) license, which permits others to distribute, remix, adapt, build upon this work noncommercially, and license their derivative works on different terms, provided the original work is properly cited and the use is non-commercial. See: http:// creativecommons.org/licenses/by-nc/4.0/

\section{REFERENCES}

1. Atkinson MA, Eisenbarth GS, Michels AW. Type 1 diabetes. Lancet 2014;383:69-82.

2. IDF Diabetes Atlas, 6th edition. https://www.idf.org/sites/default/files/ EN 6E Atlas Full 0.pdf

3. Ehehalt S, Dietz K, Willasch AM, et al., DIARY-Group Baden-Wuerttemberg. Prediction model for the incidence and prevalence of type 1 diabetes in childhood and adolescence: evidence for a cohort-dependent increase within the next two decades in Germany. Paediatr Diabetes 2012;13:15-20.

4. Elding Larsson $\mathrm{H}$, Vehik K, Bell R, et al. Reduced prevalence of diabetic ketoacidosis at diagnosis of type 1 diabetes in young children participating in longitudinal follow-up. Diabetes Care 2011;34:2347-52.

5. Winkler C, Schober E, Ziegler AG, et al. Markedly reduced rate of diabetic ketoacidosis at onset of type 1 diabetes in relatives screened for islet autoantibodies. Paediatr Diabetes 2012;13:308-13.

6. Ziegler AG, Rewers M, Simell O, et al. Seroconversion to multiple islet autoantibodies and risk of progression to diabetes in children. JAMA 2013;309:2473-9.

7. Ziegler AG, Bonifacio E., BABYDIAB-BABYDIET Study Group. Age-related islet autoantibody incidence in offspring of patients with type 1 diabetes. Diabetologia 2012;55:1937-43.

8. Insel RA, Dunne JL, Ziegler AG. General population screening for type 1 diabetes: has its time come? Curr Opin Endocrinol Diabetes Obes 2015;22:270-6.

9. Lampasona V, Schlosser M, Mueller PW, et al. Diabetes antibody standardization program: first proficiency evaluation of assays for autoantibodies to zinc transporter 8. Clin Chem 2011;57:1693-702.

10. Schlosser M, Mueller PW, Törn C, et al. Diabetes Antibody Standardization Program: evaluation of assays for insulin autoantibodies. Diabetologia 2010;53:2611-20. 
11. Törn C, Mueller PW, Schlosser M, et al. Diabetes Antibody Standardization Program: evaluation of assays for autoantibodies to glutamic acid decarboxylase and islet antigen-2. Diabetologia 2008:51:846-52.

12. Ziegler AG, Hummel M, Schenker M, et al. Autoantibody appearance and risk for development of childhood diabetes in offspring of parents with type 1 diabetes: the 2-year analysis of the German BABYDIAB Study. Diabetes 1999;48:460-8.

13. Bonifacio $\mathrm{E}$, Yu L, Williams AK, et al. Harmonization of glutamic acid decarboxylase and islet antigen-2 autoantibody assays for national institute of diabetes and digestive and kidney diseases consortia. $J$ Clin Endocrinol Metab 2010;95:3360-7.

14. Achenbach $\mathrm{P}$, Lampasona V, Landherr U, et al. Autoantibodies to zinc transporter 8 and SLC30A8 genotype stratify type 1 diabetes risk. Diabetologia 2009;52:1881-8.

15. Wasserfall C, Atkinson M, Jodoin E, et al. Glutamic acid decarboxylase and IA-2 autoantibodies in type 1 diabetes: comparing sample substrates for autoantibody determinations. Paediatr Diabetes 2000;1:10-16.

16. Bazzigaluppi E, Bonfanti R, Bingley PJ, et al. Capillary whole blood measurement of islet autoantibodies. Diabetes Care 1999;22:275-9.

17. Bingley PJ, Rafkin LE, Matheson D, et al. Use of dried capillary blood sampling for islet autoantibody screening in relatives: a feasibility study. Diabetes Technol Ther 2015;17:867-71.

18. Insel RA, Dunne JL, Atkinson MA, et al. staging presymptomatic type 1 diabetes: a scientific statement of JDRF, the Endocrine Society, and the American Diabetes Association. Diabetes Care 2015;38:1964-74.

19. Parikka V, Näntö-Salonen K, Saarinen M, et al. Early seroconversion and rapidly increasing autoantibody concentrations predict prepubertal manifestation of type 1 diabetes in children at genetic risk. Diabetologia 2012;55:1926-36.

20. Krischer JP, Lynch KF, Schatz DA, et al. The 6 year incidence of diabetes-associated autoantibodies in genetically at-risk children: the TEDDY study. Diabetologia 2015;58:980-7.

21. American Diabetes Association. Classification and Diagnosis of Diabetes. Diabetes Care 2015;38(Suppl 1):S8-16.

22. Hummel M, Ziegler AG, Roth R. Psychological impact of childhood islet autoantibody testing in families participating in the BABYDIAB study. Diabet Med 2004;21:324-8.

23. Galatzer A, Green E, Ofan R, et al. Psychological impact of islet cell antibody screening. J Paediatr Endocrinol Metab 2001;14(Suppl 1): 675-9.

24. Bennett Johnson S, Tercyak KP Jr. Psychological impact of islet cell antibody screening for IDDM on children, adults, and their family members. Diabetes Care 1995;18:1370-2.
25. Johnson SB. Psychological impact of screening and prediction in type 1 diabetes. Curr Diab Rep 2011;11:454-9.

26. Löwe B, Spitzer RL, Zipfel S, et al. Gesundheitsfragebogen für Patienten (PHQ D). 2. Auflage. Karlsruhe: Pfizer, 2002.

27. Thümer L, Adler K, Bonifacio $\mathrm{E}$, et al. German new onset diabetes in the young incident cohort study: DiMelli study design and first-year results. Rev Diabet Stud 2010;7:202-8.

28. Velluzzi F, Secci G, Sepe V, et al. Prediction of type 1 diabetes in Sardinian schoolchildren using islet cell autoantibodies: 10-year follow-up of the Sardinian schoolchildren type 1 diabetes prediction study. Acta Diabetol 2016;53(1):73-9.

29. Boehm BO, Manfras B, Seissler J, et al. Epidemiology and immunogenetic background of islet cell antibody-positive nondiabetic schoolchildren. Ulm-Frankfurt population study. Diabetes 1991:40:1435-9.

30. Schlosser M, Strebelow M, Rjasanowski I, et al. Prevalence of diabetes-associated autoantibodies in schoolchildren: the Karlsburg Type 1 diabetes risk study. Ann N Y Acad Sci 2004;1037:114-17.

31. Schatz D, Krischer J, Horne G, et al. Islet cell antibodies predict insulin-dependent diabetes in United States school age children as powerfully as in unaffected relatives. J Clin Invest 1994;93: 2403-7.

32. Neu A, Hofer SE, Karges B, et al. Ketoacidosis at diabetes onset is still frequent in children and adolescents: a multicentre analysis of 14,664 patients from 106 institutions. Diabetes Care 2009;32:1647-8.

33. Fernandez Castañer M, Montaña E, Camps I, et al. Ketoacidosis at diagnosis is predictive of lower residual beta-cell function and poor metabolic control in type 1 diabetes. Diabetes Metab 1996;22:349-55.

34. Bowden SA, Duck MM, Hoffman RP. Young children ( $<5$ year) and adolescents ( $>12$ year) with type 1 diabetes mellitus have low rate of partial remission: diabetic ketoacidosis is an important risk factor Paediatr Diabetes 2008;9:197-201.

35. Triolo TM, Chase HP, Barker JM., DPT-1 Study Group. Diabetic subjects diagnosed through the Diabetes Prevention Trial-Type 1 (DPT-1) are often asymptomatic with normal A1C at diabetes onset. Diabetes Care 2009;32:769-73.

36. Barker JM, Goehrig SH, Barriga K, et al. Clinical characteristics of children diagnosed with type 1 diabetes through intensive screening and follow-up. Diabetes Care 2004;27: 1399-404.

37. Meehan C, Fout B, Ashcraft J, et al. Screening for T1D risk to reduce DKA is not economically viable. Pediatr Diabetes 2015;16:565-72. 